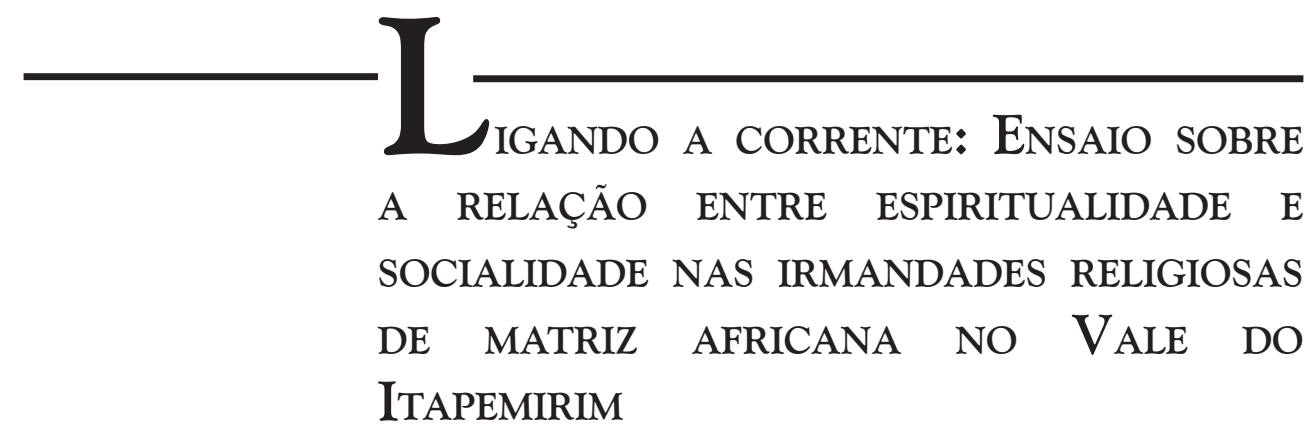

Diogo Bonadiman Goltara Universidade Federal do Espírito Santo - Vitória

Espírito Santo - Brasil

\title{
Introdução
}

Nas comunidades remanescentes de quilombos do Vale do Itapemirim, na região sul do Espírito Santo, as "irmandades de santo" cuidam das instáveis - e inevitáveis - relações entre vivos e espíritos ${ }^{1}$. Particularmente, tais instituições zelam pelas "casas de oração", locais em que o fluxo de entidades espirituais pode ser controlado ou contido segundo a orientação doutrinária - "ritmo" ou "linha" - local. Se entre os vivos os responsáveis pelos templos são chamados de "zeladores", seus "donos" são os santos padroeiros e, em alguns casos, entidades espirituais diferenciadas. Entre irmandade e santos circula uma multidão de espíritos que interagem com as irmãs e os irmãos, manifestando-se de diversas formas, seja viajando com o vento, entre sinais ou longos diálogos nos sonhos, seja incorporando em médias e médiuns. Os santos não "descem" desta última maneira ao centro, mas regem uma legião de entidades submissas que atuam em seu nome. Compondo "correntes espirituais", tais entidades trabalham em diversas atividades de cura e de limpeza com a expectativa de ascender aos planos espirituais mais elevados e distantes da "terra fria". 
Atuando junto à irmandade, os "guias de luz"3 estão em um processo de iluminação. Quando concluem suas missões no mundo material, algumas dessas entidades "sobem", notadamente os "guias de frente"4 das zeladoras ou zeladores falecidos, tornando-se espíritos consagrados. Nessa condição, podem se somar à chefia de um centro, tal qual os santos padroeiros, atuando sempre ou quase sempre no plano "do invisível”. Em todo caso, santos e entidades iluminadas estão afastados das interações cotidianas com a irmandade, mas suas ações ainda são fundamentais ${ }^{5}$. Como a relação com esses espíritos é baseada na reciprocidade, as irmandades fazem-lhes oferendas periódicas para conservar o fluxo de dádivas necessárias à vida comunitária. No entanto, uma oferenda não se basta pelos trabalhos das irmãs e dos irmãos, mas deve ser um agregado de missões oriundas de outras casas de oração. No léxico da rede esotérico-umbandista 6 , "missão" denomina um tipo de ação individual ou coletiva que leva em conta alguma forma de sacrifício pessoal e oscila entre honrar uma dívida e criar o imperativo do débito a quem se destina. Trata-se de uma dádiva a algum parceiro (ou potencial parceiro), seja uma pessoa, um santo, um guia espiritual, seja uma casa de oração. Nota-se, portanto, que o trabalho para que a oferenda seja reconhecida pelo santo deve ser contínuo.

Seguindo o emaranhado das alianças que conectam vivos e espíritos, este artigo busca explorar a relação entre religiosidade e vida social ${ }^{7}$ a partir de etnografia realizada junto com a irmandade de Menino Jesus, sediada no Zumbi, comunidade localizada na periferia do município de Cachoeiro de Itapemirim ${ }^{8}$.

As irmandades do Itapemirim classificam umas às outras a partir do contraste entre composições de duas doutrinas, a "umbandista" e a "esotérica". Os terreiros classificados majoritariamente pelo ritmo umbandista são abundantes nas áreas urbanas da região, com uma marcada influência proveniente da umbanda de outras regiões do sudeste9. Também denominada "corrente africana", essa linha tem como traço diacrítico os trabalhos das "giras" ${ }^{10}$ de boiadeiros, ciganas, baianos, crianças (erês), oguns, exus e pombagiras. Já as casas esotéricas, autodefinidas como mais "puras" do que as umbandistas, situam-se sobretudo nas áreas rurais e trabalham apenas com caboclos - do que deriva a constante designação de tais casas como "corrente de água e vela (branca)", alimentos de caboclos marinheiros, em contraste com a corrente africana, cujas entidades consomem, além de velas brancas e "traçadas", álcool e tabaco - e, eventualmente, com pretos velhos - ainda que em determinados contextos tais entidades sejam apontadas como representantes da corrente africana.

A linha esotérica tem como influência marcante o Círculo Esotérico da Comunhão do Pensamento (doravante CECP), doutrina fundada em São Paulo no ano de 1908 pelo imigrante português Antônio Olívio Rodrigues (1879-1943). Tratava-se de uma "[...] fusão característica do ocultismo e do esoterismo do século XIX e início do século XX, no caso brasileiro, marcada pelo espiritismo kardecista e pela noção de mediunidade" (Silva 2006:230). A doutrina rapidamente se espalhou pelo território nacional na primeira metade do século XX em seus templos próprios e pelo trânsito 
em outras práticas espirituais ${ }^{11}$. Na região do Itapemirim, a principal característica do CECP é postulada pela "concentração" em uma mesa central - no que se distingue da incorporação dos espíritos da umbanda nas giras. Por meio da concentração, os praticantes podem se comunicar uns com os outros por mediação espiritual, além de entrar em sintonia com os caboclos.

Apesar dessa polarização doutrinária, irmandades de diferentes linhas mantêm uma dinâmica de reciprocidade por meio da qual se constroem importantes formas de socialidade. Tal implicação produz linhas de fluxo em diversas dimensões, de tal forma que as doutrinas não subsistem senão como categorias por meio das quais as irmandades se conectam e ao mesmo tempo se diferenciam umas das outras. Parafraseando Edgar Barbosa Neto (2012), "cada casa é um caso" ou, como se diz no Vale do Itapemirim, "cada casa é um ritmo"12.

Essa multiplicidade é particularmente notável nas festas dos padroeiros. O princípio que permeia a oferenda é o de que a irmandade deve reunir missões à exaustão para o santo, não apenas dos seus membros, mas sobretudo de outras irmandades. A única forma de fazê-lo é por meio de visitas rituais às festividades de outras irmandades, interpelando-as, dessa forma, a restaurar a dívida por meio de uma visita como retribuição. Assim, uma oferenda ao padroeiro da casa sempre se confunde com um encontro de irmandades oriundas de diversos pontos da região, próximos ou distantes. O deslocamento que uma irmandade realiza entre sua casa de oração e aquela que será visitada - porque festeja os seus santos - é denominado "jornada", e quem assim se desloca, de "jornaleira" ou "jornaleiro". Assim, uma jornada nunca é um evento que se encerra em si mesmo, mas é sempre o desenvolvimento de visitas anteriores e a criação de outras que estão por vir.

Estejam elas mais próximas da linha umbandista ou da esotérica, as irmandades resguardam alguns princípios rituais em comum para formalizar a aliança, criando-a ou perpetuando-a. O "louvor", por exemplo, é um gênero de discurso visitante improvisado, sempre entoado melodicamente e versejado por uma entidade - ou um médium que frequentemente se transforma em entidade espiritual durante a performance -, repetido linha a linha pela audiência, que fala sobre a viagem, abençoa e cobra o retorno da visita. No caso de uma visita ritual, o louvor compõe-se de um emissor proveniente de uma irmandade particular e uma audiência composta por irmandades heterodoxas. Apesar disso, cobra-se com rigidez a resposta conveniente para cada ação ritual, garantindo-se, assim, a perpetuação de um diálogo composto pelos parceiros que é capaz de promover um jogo de influências, fazendo das doutrinas compósitos em constante transformação.

Assim entrelaçados, jornaleiras e jornaleiros definem-se coletivamente como "uma só irmandade" e como uma grande "rede de jornaleiros", mensurada tanto em relação ao espaço (a distância entre uma casa de oração e suas parceiras), quanto por sua densidade (o número total de alianças). Tais expressões são constantemente evocadas nas conversas entre membros de jornadas de distintas irmandades durante 
a oferenda de uma casa ao padroeiro. Nesses festivais, a casa que faz a oferenda conta com as visitas dos centros parceiros que vão ajudá-la de diversas maneiras, como na condução dos trabalhos, na recepção dos outros grupos de visitantes e no incremento e propagação da "corrente espiritual" que é produzida pelo acúmulo das jornadas e que será encaminhada ao padroeiro. Além disso, para muitos parentes e amigos, são também as ocasiões de reencontro mais corriqueiros.

A corrente espiritual traduz um movimento muito particular da população remanescente de quilombos do sul do Espírito Santo. A negação sistemática do acesso à terra historicamente levou à busca pelo trabalho nas roças de fazendeiros e nos centros urbanos. No entanto, a conexão com a ancestralidade mantém-se a despeito - e a partir - do deslocamento e da dispersão. A magnitude da corrente espiritual que flui pelas comunidades às margens do Itapemirim e é fortalecida nas oferendas aos padroeiros leva uma irmandade a circular constantemente por esse território dinâmico, desenhando pelo espaço as linhas que cintilam entre a memória e as relações sociais contemporâneas. Se as comunidades estão isoladas em pequenas ilhas por esse território, as correntes, através das jornadas, delineiam grande parte deste lugar como território étnico. No que se segue, veremos como a aliança de irmãs e irmãos, de casas de oração com "ritmos" distintos concorre para a produção contínua de socialidade na região do Itapemirim.

\section{O compromisso}

Dona Izolina chegou ao Zumbi em 1972. Sua mãe, Dona Maria, cuidava de um altar em casa, onde ambas faziam orações e davam passagem aos seus guias. Nessa época, o Vovô Jacó e o Tio Francisco, dois pretos velhos da filha, e Vovó Catarina, preta velha de dona Maria, já eram amplamente conhecidos pelos seus poderes de cura. Perto de dar à luz o primeiro filho, Izolina e seu companheiro ainda lutavam para erguer a casa da família que se consumaria com o nascimento. Mas, com o filho já nascido, a casa ainda não tinha teto, e o tempo das fortes chuvas aproximava-se. Foi quando Izolina fez uma promessa para Nossa Senhora Aparecida: se conseguissem encontrar um jeito de cobrir a casa, ela rezaria uma ladainha para a santa no dia 12 de outubro durante sete anos. Ao fim da tarde daquele mesmo dia, seu companheiro chegou em casa com o material para a construção do telhado, acompanhado de alguns camaradas para ajudar no trabalho.

Já nos primeiros anos, Izolina encontrou apoio de parentes e vizinhos para realizar sua promessa. Além da reza, todos os anos ofertava um café com bolo para as pessoas que a ajudavam e com o passar dos anos se viu obrigada a aumentar a quantidade de alimento. A ladainha tornou-se ocasião de encontro de jornaleiras e jornaleiros para celebrar o aniversário da santa e carregar sua imagem em procissão pelas ruas íngremes do Zumbi. Mesmo anunciando no sétimo ano que aquele seria o último e que, portanto, a missão estaria cumprida, no ano seguinte mais pessoas 
apareceram para rezar e jornadas de casas de oração de toda a região começaram a se dirigir para a festa no Zumbi.

"Na marca dos sete anos percebi que aquela promessa havia se tornado uma missão maior", disse-me Dona Izolina em sua casa em maio de 2011. Há um corolário sobre o pagamento de promessas derivar do número sete. A rigor, o compromisso estende-se por no mínimo sete anos, podendo ser expandido, por iniciativa do santo ou do demandante, por mais tempo, mas com a regra básica de completar outro ciclo de mesma duração. A isso denomina-se "dobrar a promessa". Ao perceber que a santa a elegera para uma missão maior do que a retribuição da dívida com o telhado da casa, Dona Izolina manteve a oferenda anual e as jornadas quase semanais a outras casas de oração. Com o passar dos anos, o que era um pequeno altar em um quarto anexo à sua casa, deu lugar a uma edificação de três pavimentos compreendendo o centro, uma cozinha comunitária e uma laje transformada em barracão. Ao lado desse complexo, em outra construção, situa-se a residência da família de Dona Izolina. Em 12 de outubro de 2013, a zeladora do Centro Espírita Menino Jesus rezou a 37ạ ladainha consecutiva para Nossa Senhora Aparecida. O relato que se segue refere-se a essa data.

Com dois meses de antecedência, Dona Izolina inaugura o "tempo da festa" em um discurso após a sessão de cura esotérica ${ }^{13}$ que acontece no primeiro domingo do mês, convidando a todas e todos para o empenho nas obrigações da irmandade. Com o dinheiro arrecadado nesse período, encomenda os ingredientes da feitura da comida, a primeira das preocupações. A cozinha, no entanto, é um espaço cuidadosamente limitado a algumas irmãs de confiança. Não à toa, pois o alimento é um dos mediadores mais eficazes de feitiços. Se uma contaminação sobrevir, o resultado será dramático para os visitantes e também para a imagem da irmandade. As mulheres que não estão no grupo seleto das cozinheiras dividem-se entre a limpeza e a decoração. No caso peculiar da disposição das imagens dos santos, se há ajudantes, todos os movimentos são administrados e supervisionados por Dona Izolina. Entre os poucos homens assíduos da irmandade, um ou outro se responsabiliza por ajustes estruturais e estéticos da casa. Nesse ano, todavia, alguns deles não cumpriram com seus deveres. Horas antes da chegada da primeira irmandade, Izolina ainda empunhava um rolo de espuma embebido em tinta branca e atado a uma longa vara para terminar o arremate dos últimos contornos da parede.

Com os rumores da chegada dos primeiros visitantes, os integrantes da banda de música da irmandade de Menino Jesus reúnem-se em frente ao altar da santa. $\bigcirc$ trompete de Cleiton, filho carnal e sucessor de Dona Izolina, puxa a primeira toada, que orquestra as vozes de outros instrumentos de sopro antes do ataque do bumbo. Este, por sua vez, prepara a caixa e os pratos. O som da banda tem poder de limpeza dos "males influídos". Dito de outra maneira, a "corrente da banda" radia as pessoas e os lugares para expulsar correntes ou restos de espíritos mandados por feitiçaria, ou que vagam sem objetivo, mas que podem causar danos. Por esse motivo, as toadas são executadas em todos os cômodos do centro, seja nos terreiros, na cozinha 
coletiva, seja mesmo nos cômodos privados da casa da família da zeladora, que nos próximos dias irão abrigar centenas de pessoas, vindas de perto ou de longe, próximas ou distantes na malha das relações da irmandade. Somente ao fim da "radiação" 14 do centro é que a banda, agora composta também por flecheiras - irmãs que, em pares, portando varetas de pau (flechas), dançam, "inspiradas" por caboclos - e pela bandeira do centro, vai receber a jornada que aguarda no portão. Nessa formação, com banda, flecheiras e bandeireira ou bandeireiro, o coletivo de humanos, objetos de poder e espíritos que inspiram ou, em certos casos, incorporam, é chamado de "campo de expiação" ou de "inspiração".

A jornada vem do município de Iúna, na região do Caparaó, e percorreu cerca de 130 quilômetros, saindo da sede de sua irmandade para chegar ao Zumbi. No portão do centro de Dona Izolina, alinha-se em um campo de expiação próprio para aguardar a chegada do grupo regido até então por Cleiton, mas em frente ao qual agora se encontra a zeladora, carregando a bandeira de Nossa Senhora Aparecida. Já na rua, ela se dirige para a bandeireira e também zeladora da jornada visitante ${ }^{15}$, com a qual realiza a solene troca de bandeiras. Aprumados enquanto um só "bate-flecha"16, descem as escadarias da casa de Menino Jesus. No caminho para o altar do templo, param em dois cruzeiros e, em cada um deles, um caboclo diferente incorpora para louvar ao santo ali assentado. Já no altar, após muitos versos endereçados à santa aniversariante, o caboclo da diretora visitante expõe o principal objetivo da sua jornada: ajudar a irmandade anfitriã a realizar sua missão com Nossa Senhora Aparecida. Mas antes de deixar o corpo da média e retornar à sua "aldeia no invisível”, ele lembra que "é preciso visitar para ser visitado", ressaltando a inexorabilidade da dívida que nesse momento foi recolocada na responsabilidade de Dona Izolina e de toda a sua irmandade.

\section{Missão, jornada e corrente espiritual}

Nesse ponto, é preciso chamar a atenção para a polivalência dos conceitos em questão e também alertar que não me cabe tipificá-los, mas explorar a multiplicidade presente em cada um deles. Tal é o caso do termo "missão". A relação entre uma média e seus guias é regida pelas missões, como atesta o comentário de Seu Manoel, durante a recepção de uma jornada no altar do Centro Menino Jesus em abril de 2016, sobre Dona Izolina: "ela não trabalha sozinha, ela sempre tem alguém [entidade] junto dela, porque é muito firme dentro da missão". Nesse caso, missão refere-se ao compromisso individual de cada irmã e irmão. A missão principal de Dona Izolina é zelar pela casa e pela irmandade. A de Seu Manoel é ser o condutor dos rituais esotéricos da casa. Tais missões podem ser assumidas espontaneamente ou designadas por um guia de luz.

A jornada é uma missão comum a jornaleiras e jornaleiros porque deriva da parceria com o padroeiro e com outras irmandades. É preciso jornalar porque a irmandade almeja receber jornadas em sua oferenda, criando a obrigação da retribuição, 
para que o santo se sinta, por sua vez, impelido a ouvir as irmãs e os irmãos durante todo o ano ${ }^{17}$. Essa malha de relações entre vivos e espíritos que se costura dentro das e entre as irmandades é a "corrente espiritual". As correntes são fluxos invisíveis que podem se materializar em determinados contextos - como no vento e no "choque santo". Mas além da percepção por tais meios, a corrente interpela suas partes a zelar pelas alianças por meio de missões. Estão ligados por uma corrente espiritual parceiros que zelam por missões recíprocas, como a média que tem a missão de cuidar de suas entidades para que estas possam cuidar das suas próprias missões, e as irmandades que jornalam para honrar o compromisso com outras irmandades. Tal complexidade do conceito de missão parece revelar a complexidade das alianças, de modo que a missão para com o santo/guia/padroeiro só se realiza através do compromisso com as outras casas e, portanto, com seus guias, conformando um emaranhado em que o vínculo horizontal, supostamente "secular", se diferencia pouco do vínculo vertical, supostamente mais "sagrado"18.

$\mathrm{O}$ ato que marca a conexão das correntes é o assentamento temporário da bandeira da jornada visitante no altar da casa de oração. Nesse momento, todas as missões são vistas como igualmente importantes, dispostas como equivalentes: i) as missões das médias e dos médiuns, que, à revelia dos constantes conflitos familiares que produzem ao jornalarem, doam quantias significativas de dinheiro para dividir os custos e viajam por seguidos finais de semana; ii) a missão dos zeladores, que pelejam para manter em ordem sua irmandade nos momentos perigosos das jornadas; iii) as missões das entidades, que por uma dependência mútua se combinam às missões pessoais de médias e médiuns. Todas essas e outras missões, pessoais ou coletivas, de vivos ou de espíritos, são indispensáveis para a constituição de uma jornada e, assim, de toda oferenda, de modo que ao mesmo tempo que se realiza uma oferta ao santo, as irmandades também reforçam as correntes que fluem em e entre si e as conecta.

Assim como uma missão envolve necessariamente outras missões, o mesmo ocorre com as jornadas. Outros deslocamentos se coadunam mais ou menos diretamente a esta jornada ritual que conecta as correntes espirituais. Além das jornadas biográficas, pelas quais jornaleiras e jornaleiros descrevem suas histórias de vida, destacam-se igualmente as jornadas das entidades espirituais, desde suas aldeias - nas águas, nas matas, em Aruanda, na Bahia - até a gira de um terreiro; e também as viagens dos espíritos "mandados por mau pensamento", isto é, os feitiços - não é raro que, em sessões de cura próximas às jornadas rituais, um ou outro mal influído diga, quando a fala lhe é outorgada, "nós jornalamos junto de vocês, mas vocês quase nunca sabem".

Nota-se, portanto, que cada irmandade é um nó em torno do qual se costura uma rede com outras irmandades ${ }^{19}$. Constituídas por contratos entre uma dupla de centros parceiros, essas redes particulares - ou segmentos de rede, se tomamos como parâmetro $a$ rede esotérico-umbandista definida como o conjunto virtual de todas as irmandades - sustentam o fluxo espiritual em movimento, e as conexões, percebidas 
sob o domínio desse fluxo, são as correntes espirituais. A rede, nesse contexto, significa um conjunto mais amplo de relações entre casas de oração, bem como demostra a magnitude da circulação do fluxo espiritual de uma casa (ou seja, quanto maior a rede, maior e mais forte é a corrente de um centro). Tal amplitude é vista com orgulho pela irmandade da casa de oração e reconhecida pelas demais irmandades como índice do poder das suas correntes. Se uma irmandade tem um grande número de conexões, isso é mérito do seu zelador e da sua irmandade no que diz respeito à "firmeza" dos médiuns - relacionada ao nível de compromisso com seus guias protetore $^{20}$-, à missão com o padroeiro e, mais diretamente, ao volume de jornadas que $\mathrm{o}$ centro é capaz de mobilizar durante o ano.

Dessa forma, a oferenda anual é a ocasião exclusiva em que a rede de uma irmandade efetivamente se reúne. Nesses eventos, encontram-se as jornadas conectadas direta e indiretamente, ou seja, aquelas que se visitam mutuamente e aquelas que não se visitam, mas que estão ligadas a uma irmandade em comum e, por esse motivo, se encontram na oferenda da casa intermediária. A despeito de todas as missões, transações e promessas que constituem, em conjunto, o mundo comum que é a rede esotérico-umbandista, a ação que reúne todas elas em um espaço-tempo único é o pagamento da promessa ao padroeiro. Nessa ocasião, o número de jornadas que visita a festa revela publicamente as benesses e qualidades dos fluxos espirituais coletados pelo santo.

\section{Dá um $S$ na corrente}

Em uma jornada para o Templo Esotérico Mártir São Sebastião e Nossa Senhora Aparecida de Flexal, município de Cariacica, em 21 de janeiro de 2012, Dona Izolina cumprimenta o anfitrião e agradece ao padroeiro da casa, São Sebastião dos Martírios, por ter guiado a sua jornada. Agradece também por todas as preces oradas naquele centro em intenção dela e dos membros de sua irmandade. Em seguida, ela pede aos guias da sua corrente que desçam para trabalhar:

Eu peço àquela força santa bendita que trabalha de $S$ em $S$, de corrente em corrente, que trabalha junto daquela fiscalização, dentro daquela presidência do invisível, dentro daquela corrente dos espíritos auxiliadores, dentro daquela corrente dos anjos removedores, dentro daquela corrente dos anjos da cercania, que trabalha junto de nós, que trabalhe junto dos nossos irmãos, que levante aquele vento santo que trabalha na aurora, que trabalha na alvorada e na madrugada, para que esse vento possa passar por aqui, e que se existe alguma influência, alguma coisa negativa junto de nós que se apanharam ou toparam ou encontraram conosco pela beira das estradas encostado nos matos ou parado por alguma sombra, eu peço àquela força santa buscadora, aquela corrente 
trabalhadora, que se encontra trabalhando no invisível nessa hora, que passe por aqui, que passe entre todos nós.

Nesse momento crucial para conectar ou fortalecer a conexão das irmandades, as correntes espirituais do centro de origem da jornada, enviados por uma força conectora ("força santa bendita que trabalha de $S$ em $S$ "), cuidarão para que nenhuma interferência, nenhum espírito mal intencionado, entre nesse circuito. Em um louvor que se segue a esta oração, a zeladora deposita a bandeira de São Sebastião no altar, selando, então, a ligação das correntes. Uma corrente de caboclos marinheiros arremata: "Canoeiro rema o barco/Rema o barco devagar/Ai meu Deus como é bonito/ Essas correntes se encontrar".

Gostaria de retomar a investigação elaborando uma reflexão a partir de dois campos de significação convencionais da palavra "corrente", um deles ligado ao encarceramento, que é derivado da conexão de uma corrente, e outro mais relacionado aos fluxos ${ }^{21}$. Uma das imagens mais próximas ao primeiro é a corrente de ferro, constituída a partir de elos fechados. Já o segundo é derivado do movimento dos fluidos, como cursos das águas e as correntes elétricas. Ainda que possamos destacar situações em que um desses grupos de significados seja mobilizado como foco, é difícil pensar o isolamento de cada um deles em qualquer contexto. Um exemplo simples: o curso de um rio restringe uma quantidade de água a movimentar-se em uma determinada direção. Por outro lado, um grilhão que encarcera é responsável pela restrição do fluxo de um sujeito. Mas uma corrente é também algo que une pelo propósito da dispersão, ou seja, da circulação de fluidos que, não fosse dessa forma, estariam represados, tal como as correntes sanguíneas, as correntes marítimas, as ondas de migração, a fuga.

Entre as irmandades esotérico-umbandistas do Vale do Itapemirim, o termo corrente espiritual adquire alguns contornos especiais ao transitar pelos dois polos significativos. É uma corrente que igualmente conecta e faz fluir. Porém, em oposição aos grilhões do cativeiro - a corrente que cerceia, que prende, construída por argolas de ferro fechadas, as correntes que cortam o fluxo dos escravos nas senzalas, denunciadas pelos passos sofridos dos pretos velhos nas giras umbandistas -, a corrente espiritual é unida por elos em $S$, segundo a fórmula que dá título a esta sessão, utilizada por jornaleiras e jornaleiros para ligar - "dar um S" - a corrente entre irmandades.

Além disso, cada $S$ é composto de outras correntes e outros SS, como um fractal: uma casa de oração é um $S$ da corrente que é a rede de irmandades; por outro lado, um centro espírita faz parte da corrente umbandista ou da corrente da comunhão do pensamento; uma doutrina, umbandista ou esotérica, é composta pelas suas correntes de entidades espirituais específicas, e assim por diante. Os SS são os pontos da rede em diferentes escalas, de modo que a noção de corrente eleva essa rede aparentemente homogênea ao status de uma rede híbrida, fazendo com que cada missão particular se torne uma missão coletiva ${ }^{22}$. 
Uma corrente construída por SS depende da tensão para permanecer coesa. $\mathrm{Na}$ corrente espiritual, quando nos aproximamos de cada $S$, vemos que ele próprio é formado por outros elos que são tensionados por missões. Vimos que as missões são relações de reciprocidade, o que significa que o pêndulo da dádiva deve se manter em movimento, alterando as posições entre doador e receptor. Uma corrente espiritual é um conjunto vasto de parcerias desse tipo entre o mundo material e o invisível. Se qualquer $S$ se soltar, todo o fluxo para, o que pode gerar danos a todos envolvidos na corrente. Um fluxo que cessa, represa, acumula e pesa. Toda missão é "pesada", dizse, e irmãs e irmãos têm ao menos uma "cruz"23 para carregar consigo. Mas jornalar também é uma forma de aliviar o peso. A esse respeito, são constantes os testemunhos de grande sensação de leveza em dois momentos, quando se retorna de uma jornada e quando o médium volta à consciência após uma sessão de incorporações.

Segue-se que uma corrente é também uma sucessão de missões que, apesar de se ligarem a uma pessoa ou uma irmandade, são sempre coletivas, pois cada uma delas interfere nas demais missões. A maior dificuldade em se definir uma corrente espiritual dá-se em função de relacionar parcerias de categorias distintas. Assim, ao mesmo tempo que temos a corrente entre irmandades, há outras correntes, como a que liga uma irmã a uma irmandade e, por conseguinte, a um santo, e a que relaciona um médium a uma corrente de guias de luz. É preciso destacar que as missões exercem forças umas sobre as outras, compondo, assim, uma corrente que não deve ser visualizada como uma linha única, mas como um emaranhado de ligações e de fluxos em diversas escalas.

Tentarei fazer um mapeamento de algumas manifestações da corrente espiritual a partir da trajetória de um jovem jornaleiro. Cleiton de Paula é o mais novo dos cinco filhos carnais de Dona Izolina e o único entre os irmãos que segue firme na missão espiritual do Centro Menino Jesus. Aos 7 anos de idade foi escolhido pelo preto velho Vovô Congo para ser seu aparelho. Apesar dos conflitos que surgiram entre médium e guia, uma vez que Cleiton não aceitou a missão de imediato, em pouco tempo o Vovô Congo de Cleiton assumiu um lugar na irmandade quase tão destacado quanto o do Velho Jacó, o chefe da casa, que é o guia de frente da zeladora. Se este ocupa o principal assento do terreiro e é obrigatoriamente o primeiro preto velho a ser consultado, seja para uma cura, seja para algum detalhe da doutrina da casa, o Vovô Congo é mais extrovertido, tratando com grande carisma irmãs e irmãos.

O prestígio e o reconhecimento público do seu poder fez com que o velho Congo se tornasse a segunda voz da irmandade. Tudo leva a crer, contudo, que a entidade não seria assim reconhecida não fosse sua parceria com Cleiton, na mesma medida em que ser aparelho desse guia é parte da importância que o médium tem dentro da irmandade. Se Cleiton é o $S$ que liga o Vovô Congo à irmandade de Menino Jesus e o posiciona acima de outras entidades parceiras da irmandade, o preto velho é o $S$ que sustenta o jovem com considerável influência na hierarquia da casa. Nesse sentido, a mesma corrente que liga médium e guia descortina-se em outras manifestações da 
corrente, como a "corrente mediúnica", a "corrente das pretas e dos pretos velhos" da irmandade, a "corrente da coroa do médium", isto é, o conjunto de todos os espíritos que incorporam no mesmo aparelho.

Com pouco mais de 20 anos, Cleiton tornou-se "pai de santo", denominação pouco usual na rede esotérico-umbandista, mas regra de tratamento entre as filhas e filhos que têm a Cleiton como líder religioso. Na prática, o filho da zeladora deu início a uma irmandade própria e em parte independente da comunidade dirigida por sua mãe. Nessa mesma época, seu crescimento deparou-se com a liderança forte de Dona Izolina e desencadeou uma série de conflitos relacionados ao ritmo doutrinário da irmandade. Cleiton então mudou-se para o município de Ibatiba, na região do Caparaó, onde esteve perto de erguer a sua própria casa de oração e de dar início de fato à sua própria irmandade ou, antes, à irmandade de Vovô Congo. Durante os dois anos que permaneceu na cidade, Cleiton fez visitas quase semanais ao Centro Menino Jesus, pois ali havia um $S$ fundamental e incontornável de sua corrente espiritual, sua "raiz", nas palavras de Dona Graça, uma das irmãs mais antigas de Menino Jesus, em entrevista no dia 6 de dezembro de 2012. Ela acrescenta que o médium deve buscar sua força ou sua firmeza no centro em que foi iniciado - "Não adianta cavucar para outro lugar, a corrente dele está aqui”.

Esta acepção da corrente vinculada à "raiz" parece apontar para outro nível de complexidade, ligando as associações sincrônicas ou horizontais aos vínculos genealógicos, no sentido do "parentesco de santo", pois, embora Cleiton seja filho biológico de Dona Izolina, tal corrente diz respeito ao seu desenvolvimento. Nesse sentido, todas as irmãs e irmãos desenvolvidos em uma casa de oração mantêm-se ligados à corrente daquela casa e, no caso de abrirem as suas próprias casas, estas estarão ligadas inexoravelmente à primeira. Como se vê, esta corrente que corre com a "raiz" de uma pessoa distingue-se de todas as outras por ser permanente a despeito da manutenção de sua força. A modulação aqui não parece ser de ligação e de corte, mas de firmeza e de fraqueza.

Além de haver essa corrente com as irmãs e os irmãos nela iniciados, uma casa de oração também possui uma corrente com outras casas de oração. Ligadas, as irmandades amparam-se, comunicam-se, enviam rondas espirituais de limpeza: "Hoje eu recebi uma alertação no pensamento de que o pessoal lá do Simão Pedro está precisando da nossa ajuda”, proferiu Mãe Izolina ao acender uma vela no início de um trabalho em uma quarta-feira de junho de 2013. Diz-se que quanto maior o número de ligações de uma irmandade com outras, mais forte é sua corrente espiritual.

Além de conectar, é pela corrente que viajam os espíritos e é por meio da participação em alguma missão que esta força pode ser acessada. É por ela que chegam os guias, vindo de suas aldeias no invisível - de Aruanda (pretos velhos), do mar (calungas e caboclos marinheiros de Imaculada Conceição), das matas (caboclos flecheiros de São Sebastião), das campinas (boiadeiros), das encruzilhadas (exus e pombagiras) - para o corpo dos seus aparelhos. É também por ela que algumas entidades, sobretu- 
do os caboclos flecheiros, jornalam junto com os jornaleiros vivos. Conexão e fluxo são características que cooperam na corrente. Em suas análises profundas a respeito das correntes espirituais, Cleiton afirma que as missões movimentam as correntes, e sem movimento, sem missão, não pode haver ligação duradoura entre SS.

Há uma expressão corporal comum nos rituais esotérico-umbandistas que demonstra com clareza a fluidez das correntes. Em momentos de grande concentração de correntes "positivas" ou "negativas" - isto é, benéficas ou maléficas -, como nos rituais de limpeza e de cura, os zeladores podem produzir situações de grandes descargas energéticas pelos corpos dos médiuns, os chamados "choques santos". Estes são percebidos pelos próprios médiuns e por toda a assembleia como signo da passagem de uma corrente espiritual. Nesse momento, todas as pessoas presentes realizam uma espécie de autolimpeza, passando as mãos desde a cabeça até as extremidades do corpo com o intuito de extrair qualquer vestígio da corrente que certamente passou por ele. É também por este motivo que se evita cruzar braços ou pernas durante o andamento de um ritual.

Ademais, as correntes inscrevem-se no espaço do centro, e suas marcas invisíveis atuam como condutos para que todas as correntes possam fluir. No Centro Espírita Menino Jesus, os caminhos realizados pelas giras de entidades espirituais rodam sempre em sentido anti-horário. Todas as correntes que vão se sucedendo repetem o mesmo movimento até a chegada da corrente dos pretos velhos, que realiza uma gira diferente. Eles dançam a gira com os passos do caxambu, uma dança que é propriedade daqueles que foram feitos escravos. Sem se demorar na gira, os vovôs e as vovós sentam-se em seus troncos. E a partir desse momento são as pessoas não incorporadas que refazem o caminho dos espíritos. Forma-se então uma fila, e os pacientes vão passando pelos pretos velhos, um a um, a partir do vovô ou vovó da zeladora, para ser aconselhado e abençoado. Não é permitido romper esse circuito. Em uma das primeiras sessões de que participei, sem saber dessa regra, ofereci a outra pessoa o meu lugar na fila e fui imediatamente repreendido por um vovô: "Assim você quebra a corrente".

De um modo geral, o centro é também identificado como uma corrente apesar de abrigar inúmeras correntes. Ela é definida pelas características das correntes das entidades espirituais que frequentam os centros, que realizam ali as suas missões. Portanto, se em um centro trabalham as correntes dos Calunga e as correntes que radiam os médiuns nas curas esotéricas, esse centro é uma "corrente de Imaculada". Por outro lado, se nele trabalham os guias da umbanda, ele é da "corrente africana". No entanto, a maioria dos centros da rede esotérico-umbandista trabalham com as duas qualidades de correntes, diferindo em proximidade a um polo ou outro, ou seja, o quanto está aberto para a presença de correntes de outras doutrinas.

Finalmente, há ainda um modo especial de criar e conduzir uma corrente por meio da palavra. Em quase todos os rituais esotérico-umbandistas, há um lugar importante para a oração, geralmente antes e após os rituais de incorporação espiritual. Considera-se que as palavras de uma prece não são apenas descritivas, mas sim cria- 
tivas, e, como a fumaça das velas, que "elevam" os pedidos para os santos, as palavras rezadas viajam entre os planos material e espiritual, entre outras coisas, realizando limpezas e provocando a descida de uma corrente de entidades ${ }^{24}$. Com frequência, uma prece inicia-se vagarosa, destacando o agradecimento à divindade, e cresce em intensidade, ritmo, chegando à voz de comando. O que essa voz produz é capaz de atravessar os corpos dos médiuns, fazendo com que estes incorporem determinados espíritos. Vejamos mais de perto este processo a partir de uma prece rezada por Seu Manoel ao "despertar" (do estado de radiação) uma corrente de médiuns em uma sessão de cura esotérica no Centro Menino Jesus em um domingo do final da primavera de 2012:

Senhor Deus de misericórdia, essa prece é uma prece santa e poderosa, cada palavra dessa prece forma um S, com o $S$ ligado, forma-se uma corrente, corrente essa, uma corrente condutora, uma corrente elevadora, uma corrente separadora que possa separar os fluidos do mal da mente da consciência da santa mediunidade. É uma corrente desconjuradora, com ela nós não desconjuramos o anjo da guarda nem as almas protetoras nem essa corrente maravilhosa que por aqui está trabalhando, mas desconjuramos todas as classes de espíritos de mau pensamento, espírito de olho grande, espírito de inveja, espírito de bruxaria, espírito de quebrante e mau-olhado que muitas vezes mandado seja por homem ou mulher de mau pensamento e mau coração dentro dessa corrente desconjuradora. Pois seja desconjurado e apartado e ponha-se fora dessa casa e torna pro invisível em nome das três pessoas distintas e poderosas da Santíssima Trindade.

A prece de seu Manoel é criadora de uma corrente; e esta corrente é, ela própria, a prece. E, enquanto esse círculo - a roda que a cada giro realiza algo novo - é criado, a prece ainda narra o seu próprio movimento transformador. Se determinadas palavras proferidas no espaço-tempo sagrado do centro são SS, a corrente depende da conexão entre essas palavras, isto é, depende do rezador, envolvido com sua corrente espiritual e com a sua missão ao pronunciar a cadeia de palavras que irá se transformar em uma corrente.

Ao desdobrar a etimologia de "prece" com sua moderna sinonímia "oração" e "reza", Pina-Cabral (2009), além de conferir atualidade à definição de Mauss (1981) da prece como um rito oral que, de súplica, chega à voz de autoridade sobre a divindade, oferece uma ferramenta para desmembrarmos a corrente. Pina-Cabral chega à conclusão de que as nuances de cada um dos termos, embora fazendo parte de um mesmo campo semântico, remetem a posições distintas no sistema comunicativo: em reza, o foco está na pessoa que realiza o rito oral; já em prece, na divindade; em oração, no "instrumento de comunicação" (Pina-Cabral 2009:19). Assim, se as palavras têm a virtude de serem SS de uma corrente, é apenas por seu encadeamento em uma 
oração, realizado por um rezador, o que fará com que a prece seja verdadeiramente eficaz, mobilizando as entidades espirituais que irão responder à súplica-comando de "separar" os fluidos bons dos maus, de dirigir-se a determinados lugares, de elevar as preces para os santos.

É bem possível que encontremos muitos outros significados específicos para a palavra corrente no interior da rede esotérico-umbandista. $O$ fato de o termo ser utilizado em diversos contextos não quer dizer que todas as correntes sejam a mesma coisa e tampouco implica em significados distintos e isolados. Algo mais complexo ocorre nesses usos em contextos distintos. Quando se diz que uma conexão qualquer é uma corrente, por exemplo, que entre duas pessoas há uma corrente ligada, toda a força significativa dos contextos em que o termo é utilizado é trazida junto com sua enunciação (Wagner 2010:79-80). Assim, se uma prece é uma corrente, sua força deriva das demais correntes de um centro, das correntes entre guias e médiuns e das correntes ligadas com outras irmandades, por exemplo. Nesse sentido é que se pode dizer entre os jornaleiros que uma prece rezada por um zelador de uma irmandade com uma corrente firme é mais eficaz que outras com correntes menores, isto é, com poucas conexões por jornadas.

\section{A distribuição das correntes}

"A corrente deve rodar", dizem as jornaleiras e os jornaleiros. É perigoso conter o fluido santo. A corrente composta por SS só se mantém unida se continuar tensionada, de modo que uma corrente sempre está em movimento, e este movimento é tributário das missões. As relações que ligam os SS dependem de esforços contínuos para se manterem rodando, caso contrário, elas irão afrouxar e a corrente irá se desfazer. Como entoado no ponto de caboclos: "São Jorge que fez a roda/Caboclo que vem rodar/Sou marinheiro/Moro nas ondas do mar/Marinheiro vai-se embora/Você fica no lugar".

Como foi dito, as correntes espirituais são caminhos por meio dos quais as entidades espirituais transitam pelos planos de existência material e espiritual. É importante ressaltar, no entanto, que o movimento das correntes não apenas torna visíveis as entidades espirituais, já que a sua translação se dá do mundo invisível para o material, mas as coloca em cooperação com as filhas e os filhos de santo. É o que o ponto acima parece afirmar. A roda configura-se como o movimento da corrente que emana de São Jorge, que habita um plano inacessível para os seres vivos, e é transportada para o mundo material por meio da missão dos caboclos, que, por sua vez, a deixam ao encargo da irmandade.

Distribuir uma corrente é uma ação importantíssima após certos rituais de cura esotéricos. Nas sessões dominicais do Centro de Dona Izolina, os médiuns, ao redor da mesa das "Três Tábuas da Lei" ${ }^{25}$, dão passagem às "correntes procuradoras", que irão vasculhar a vida do paciente em busca de espíritos maléficos mandados por 
mau-olhado ou por feitiçaria. Ao encontrá-los, tais correntes fazem com que esses espíritos sejam incorporados nos médiuns para que possam falar o motivo de sua presença na vida do paciente. Após a sessão, essas correntes devem ser reenviadas para o invisível levando com elas as missões praticadas no centro. Esta etapa comum a vários rituais denomina-se "consumação das missões". Ao mesmo tempo, o médium irá se reencontrar com o seu "anjo de guarda"26.

Não devemos confundir a distribuição das correntes com o "despacho". Enquanto no primeiro caso se trata de fazer uma corrente de missão, isto é, um coletivo de espíritos de luz de uma mesma ordem que transita entre os planos de existência, seja "subindo" (do material para o espiritual), seja "descendo" (do espiritual para o material) para realizar uma missão, o despacho é a expulsão controlada de males influídos. Uma vez capturadas, essas correntes indesejadas são "entregues" ao cruzeiro do padroeiro do centro, que cuidará do destino de tais correntes, ou à porta do centro, para a rua. Os "fiscais" da casa - zelador, diretor, presidente, fiscal de porta -, os responsáveis por dialogar com e conduzir as correntes e os anjos de guarda dos médiuns, cuidam para que as correntes não sejam dispersadas pelo centro e pela irmandade, inclusive protegendo as famílias e os círculos sociais de cada membro.

Como as entidades espirituais são "missionárias", tanto quanto os filhos e filhas de santo, a vinda das correntes para trabalhar com a irmandade é vista também como distribuição. Nesse caso, os vivos devem zelar pelas missões dos guias espirituais, de modo que elas continuem a trabalhar por meio das conexões entre as correntes. Assim, quando um guia de luz "solta" um ponto, a irmandade deve "segurar" o canto para que a benção tenha efeito; o zelador, os médiuns e as médias cumprem as suas funções para que as missões das entidades sejam conduzidas ao plano material.

Sobre o movimento de distribuir as missões de cura realizadas no centro, Dona Izolina explicou ao fim de um trabalho de cura esotérica no primeiro domingo de dezembro de 2012:

A corrente não pode ficar aqui. Tem que distribuir essa corrente, esse corpo de missão que foi passado aqui. Tem que levar ela para lá porque vai distribuir ela junto da corrente flecheira. É uma corrente navegadora que trabalha nos astros, no sertão das matas, são esses caboclos que vêm fazendo as defumações deles, são eles que vêm fazendo essas ligações nessas correntes, são eles que vêm apanhar e levantar e distribuir essa corrente para onde ela tem que ir, para onde ela tem que ficar para entregar. Porque tem um guarda no invisível que está na guarda desse expeditório, dessa missão que passou, de tudo o que nós estamos fazendo aqui.

De nada valeria todo o trabalho de cura que ocupou a irmandade de Menino Jesus em toda a manhã de domingo se a missão não for entregue para instâncias 
superiores. $\mathrm{O}$ trabalho não para, como a roda não deve parar. Por mais que ao fim dos trabalhos os missionários vivos possam se recolher em suas casas para descansar, a missão permanecerá em movimento, agora ao encargo das entidades espirituais. Vemos assim que tanto as missões dos guias de luz são continuadas pela irmandade, quanto as missões da irmandade o são pelas entidades espirituais. Tudo o que se realiza na rede esotérico-umbandista é fruto de parceria entre vivos e espíritos. Se entendemos a composição de uma corrente como um fluxo de mediações, ou seja, de conexões em SS, é inevitável que levemos em consideração a integração de seres humanos e entidades espirituais nas irmandades de santo ${ }^{27}$. A equivalência e a mutualidade das missões faz com que todo tipo de ação espiritual seja importante para as correntes. Tal integração pode ser abordada tanto a partir da composição da pessoa quanto da entidade espiritual, como vimos na trajetória de Cleiton e do Vovô Congo.

Assim como o conceito de corrente, o uso do conceito "distribuição" é disperso por vários contextos relacionados. No geral, as distribuições transportam as missões, de onde quer que elas provenham, dos seres humanos ou dos espíritos, evidenciando que as relações sociais não são constituídas somente por humanos. Além disso, ela demonstra que a corrente, que temos visto ser um importante elemento conectivo entre as irmandades de santo das comunidades remanescentes de quilombos do Vale do Itapemirim, atravessa as delimitações de indivíduo e sociedade sem respeitar suas margens.

\section{Considerações finais}

Os fluxos são infinitos, múltiplos, indiscerníveis. Eles emanam dos sentimentos humanos, das relações sociais que envolvem também o mundo dos espíritos. Nesse meio indiscernível, as correntes são tramas construídas em cooperação entre os centros, os médiuns e os espíritos, que definem parte desse fluxo por cortes ("correntes separadoras"), continuidade ("correntes condutoras") e parcerias ("correntes elevadoras"). A multiplicidade das correntes aponta para o modo como a rede esotérico -umbandista se desenvolve a partir de fluxos em suas imbricações "macro" e "micro", "molar" e "molecular" (Deleuze e Guattari 1997:99).

As correntes espirituais, por agirem em todos os níveis, micro e macrossocial, e por serem necessariamente emaranhadas umas nas outras, assinalam a conectividade que aqui destacamos e à qual não se pode designar predefinições de indivíduos ou de coletivos. As entidades que compõem o "povo jornaleiro" (espíritos, médiuns, jornaleiros, irmandades, casas de oração) são perpassadas pelas linhas das correntes e por elas constituídas, do que se compreende a fluidez das formas de tais entidades. "O espírito é um vento", mas pode se condensar em uma voz ou se dispersar em correntes. Ao término de um ritual de chegada, a bandeira da jornada visitante é depositada no altar da irmandade local e, tanto quanto a própria jornada, que passa a integrar o campo flecheiro da irmandade até sua subsequente reunião para a despedida, tornase parte indistinguível do conjunto de hierofanias relacionadas ao santo. Da mesma 
maneira, a parceria entre médium e guias modula-se de acordo com a presença de ambos nas correntes, definindo não apenas a "firmeza" de tal aliança, mas também médium e guia. Pode-se dizer, por fim, que os jornaleiros habitam e são habitados pelas correntes e que as pessoas são desdobramentos de suas próprias jornadas ${ }^{28}$. De todo modo, as correntes são fluxos ("fluidos santos"), e estes, na dispersão e na composição, são forças ("crença e desejo", de acordo com Tarde [2007]) que os transformam e que são necessários para a sua existência.

Remeto-me também às "topologias sociais" descritas por Mol e Law (1994), sendo elas as "regiões", as "redes" e os "fluidos". Embora os três modos convivam por exemplo, uma casa de oração vale-se de uma definição espacial com fronteiras fixas em determinadas situações, ainda que, como temos visto, ela possa ser descrita tanto como conectada por uma rede como pertencendo a uma topologia social fluida -, é possível caracterizar a rede de jornaleiras e jornaleiros esotérico-umbandista como um fluido. Um mundo fluido, nesse arcabouço teórico, é um mundo em movimento ${ }^{29}$.

Finalizo evocando a imagem da roda nas comunidades negras rurais do Itapemirim. Muito além de configurar o movimento dos espíritos no terreiro ou das irmãs e irmãos que seguem seus passos nos rituais, é o circuito das filiações entre pessoas de uma mesma genealogia de santo e da aliança produzida pelos jornaleiros, mas é também o traçado da integração entre tais relações. A circulação de pessoas e entidades espirituais pela região do Vale do Itapemirim produz não só a coletividade, mas também o próprio território, território este que não deve ser visto como fixo, cercado, mas aberto aos fluxos e aos giros de cada nova jornada.

\section{Referências Bibliográficas}

ARAÚJO, Wladimir Sena. (2002), "A Barquinha: espaço simbólico de uma cosmologia em construção". In: B. Labate e W. S. Araújo (orgs.). O uso ritual da ayahuasca. Campinas: Mercado das Letras/Fapesp. AUSTIN, John L. (1962), How to Do Things with Words. New York: Oxford University Press.

BANAGGIA, Gabriel. (2008), Inovações e controvérsias na antropologia das religiões afro-brasileiras. Rio de Janeiro: Dissertação de Mestrado em Antropologia Social, Museu Nacional, UFRJ.

(2015), As forças do jarê. Religião de matriz africana da Chapada Diamantina. Rio de Janeiro: Garamond.

BARBOSA NETO, Edgar R. (2012), A máquina do mundo: variações sobre o politeísmo em coletivos afro -brasileiros. Rio de Janeiro: Tese de Doutorado em Antropologia Social, Museu Nacional, UFRJ.

BIRMAN, Patrícia. (1985), "Registrado em cartório, com firma reconhecida: a mediação política das federações umbandistas”. Cadernos do ISER, Umbanda e política, $\mathrm{n}^{\circ} 18$. Rio de Janeiro: Editora Marco Zero.

(1995), Fazer estilo criando gênero. Possessão e diferenças de gênero em terreiros de umbanda e candomblé no Rio de Janeiro. Rio de Janeiro: Ed. UERJ/ Relumé Dumará.

BITTER, Daniel. (2010), A bandeira e a máscara: a circulação de objetos rituais nas folias de reis. Rio de Janeiro: 7Letras.

BROWN, Diana. (1985), "Uma história da umbanda no Rio". Cadernos do ISER, Umbanda e política, $\mathrm{n}^{\circ}$ 18. Rio de Janeiro: Editora Marco Zero. 
BRUMANA, Fernando e MARTÍNEZ, Elda. (1991), Marginália Sagrada. Campinas: Editora da Unicamp. Tradução de Rúbia Prates Goldoni e Sérgio Molina.

DELEUZE, Gilles e GUATTARI, Félix. (1997), "O liso e o estriado". In: . Mil Platôs: Capitalismo e esquizofrenia. São Paulo: Editora 34. Vol. 5. Tradução Aurélio Guerra, Ana Lúcia de Oliveira, Lúcia Claudia Leão e Suely Rolnik.

GOLTARA, Diogo Bonadiman. (2010), Santos Guerreiros: relatos de uma experiência vivida nas jornadas das Folias de Reis do Sul do Espírito Santo. Brasília: Dissertação de Mestrado em Antropologia Social, UnB.

. (2014), Dá um S na corrente: a rede esotérico-umbandista às margens do Rio Itapemirim. Brasília: Tese de Doutorado em Antropologia Social, UnB.

HOLBRAAD, Martin. (2006), "The power of powder: multiplicity and motion in the divinatory cosmology of Cuban Ifa (or mana, again)”. In: A. Henare, M. Holbraad \& S. Wastell (eds.). Thinking through things: theorising artefacts ethnographically. Abingdon, UK: Routledge.

HOUAISS, Antônio e VILAR, Mauro de Salles. (2001), Dicionário Houaiss da Língua Portuguesa. Rio de Janeiro: Objetiva.

INGOLD, Tim. (2011), Being Alive: Essays on movement, knowledge and description. New York: Routledge.

LATOUR, Bruno. (2007), Reassembling the Social: An Introduction to Actor-Network-Theory. UK: Oxford University Press.

LUCINDA, Maria da Consolação. (2012), Umbanda e religiões de matriz africana em Valença, estado do Rio de Janeiro. Rio de Janeiro: Tese de Doutorado em Antropologia Social, Museu Nacional, UFRJ.

MALINOWSKI, Bronislaw. (1978), Os Argonautas do Pacífico Ocidental. São Paulo: Abril Cultural, 2a ed. Coleção Os Pensadores.

MAUSS, Marcel. (1981), "A prece”. In: . Ensaios de Sociologia. São Paulo: Perspectiva. (2003), "Ensaio sobre a dádiva". In: . Sociologia e antropologia. São Paulo: Cosac \& Naify. Tradução de Paulo Neves.

MOL, Anemarie; LAW, John. (1994), "Regions, Networks and Fluids: Anaemia and Social Topology". Social Studies, vol. 24, no 4: 641-671.

OCHOA, Todd R. (2010), Society of the dead: Quita Manaquila and Palo in Cuba. Berkley, Los Angeles and London: University of California Press.

OLIVEIRA, Isabela. (2011), "Um desafio ao respeito e à tolerância: Reflexões sobre o campo Daimista na Atualidade”. Religião e Sociedade, vol. 31, n²: 154-178.

PEDREIRA, Carolina S. (2010), Irmãs das Almas: rituais de lamentação na Chapada Diamantina. Brasília: Dissertação de Mestrado em Antropologia Social, UnB.

PEIRANO, Mariza. (2002), "A análise antropológica de rituais". In: O dito e o feito: ensaios de antropologia dos rituais. Rio de Janeiro: Relume Dumará/Núcleo de Antropologia da Política/UFRJ, PEREIRA, Luzimar P. (2011), Os giros do sagrado: um estudo etnográfico sobre as folias em Urucuia, MG. Rio de Janeiro: 7Letras.

PINA-CABRAL, João. (2009), "A prece revisitada: Comemorando a obra inacabada de Marcel Mauss". Religião e Sociedade, vol. 29, n 2: 13-28.

SILVA, Eliane Moura. (2006), "Similaridades e diferenças entre estilos de espiritualidade metafísica: o caso do Círculo Esotérico da Comunhão do Pensamento (1908-1943)”. In: A. C. Isaia. Orixás e Espíritos: o debate interdisciplinar na pesquisa contemporânea. Uberlândia: EDUFU.

STRATHERN, Marilyn. (2014), "Cortando a rede". In: São Paulo: Cosac Naify. Tradução de Luísa Valentini. . O efeito etnográfico e outros ensaios.

TAMBIAH, Stanley J. (1985), Culture, Thought, and Social Action. An Anthropological Perspective. Cambridge, Mass.: Harvard University Press.

TARDE, Gabriel. (2007), Monadologia e Sociologia e outros ensaios. São Paulo: Cosac Naify.

VELHO, Yvonne Maggie Alves. (1975), Guerra de Orixá: um estudo de ritual e conflito. Rio de Janeiro: Zahar Editores.

WAGNER, Roy. (2010), A invenção da cultura. São Paulo: Cosac Naify. 
Religião e Sociedade, Rio de Janeiro, 36(1): 34-55, 2016

\section{Notas}

1 Este trabalho é resultado de pesquisa etnográfica realizada entre 2011 e 2013 e retomada em 2015 por meio de uma pesquisa de pós-doutorado (PGCS-UFES/CAPES/FAPES), atualmente em desenvolvimento. Todas as falas de interlocutores transcritas, exceto uma entrevista - indicada no texto - e as falas rituais, que foram gravadas, são registros do diário de campo realizados em diferentes momentos do período citado. Sou muito grato a Carolina Pedreira pela leitura atenta e pelo diálogo para a construção deste trabalho. Agradeço também a Christine Chaves pela leitura cuidadosa e pelos comentários precisos.

2 "Terra fria" é o plano material, onde vivem os humanos; por outro lado, o "invisível" é terreno dos espíritos.

3 A despeito da multiplicidade dos espíritos, há uma divisão importante entre eles. Os "guias de luz", que "trabalham com a caridade" nas casas de oração, habitam as campinas, o mar ou Aruanda, lugares sagrados denominados genericamente como "o invisível". Por sua vez, o "povo de rua" mora nas encruzilhadas seculares e pode ser composto por "doutrinados" - trabalhando de acordo com a regência dos espíritos superiores de uma irmandade - ou "insubordinados" - aqueles que vagam pelo mundo, mas que igualmente se manifestam nas casas de oração, em geral como feitiço. Em ambos os casos, são espíritos que não almejam "subir" ou se tornarem "iluminados".

4 Entidade espiritual mais importante entre as inúmeras que podem se manifestar em um médium, "aparelho" ou "cavalo". Em geral, são aquelas que primeiro incorporam e, assim, abrem o caminho dos demais espíritos em um pessoa.

5 Doravante incluirei as entidades espirituais iluminadas na categoria santo ou santo padroeiro. É certo que não devemos confundir tais espíritos, sobretudo pelo fato de que as entidades, mesmo tendo subido, podem fazer visitas esporádicas à irmandade por meio da incorporação, possibilidade não existente para os santos. Se assim procedo é porque busco focar a característica da elevação, comum a ambos.

6 Utilizo o termo "rede esotérico-umbandista" para designar a comunidade de jornaleiras e jornaleiros que, como visto, é transversal às duas doutrinas e opera uma influência mútua entre elas.

7 A relação entre religião e estrutura social é, talvez, o principal problema da antropologia das religiões, tendo sido norteador dos estudos sobre os povos e comunidades de terreiro no Brasil. Decorre que, em muitos casos, o arcabouço teórico a respeito do que se entende por estrutura social (brasileira) acaba por determinar o tipo da relação. A respeito da influência do conceito de estrutura social nas análises sobre as religiões afro-brasileiras na segunda metade do século XX, ver Banaggia (2008).

8 Ainda que a etnografia desta pesquisa esteja contextualizada no Zumbi, junto à irmandade de Menino Jesus, muitas outras casas de oração foram visitadas, principalmente nas oferendas aos padroeiros.

9 A maior parte dos centros umbandistas visitados nesta pesquisa são certificados por federações fluminenses. Existem inúmeros trabalhos sobre as federações de umbanda surgidas no início do século XX em resposta à reprimenda estatal e social às religiões de matriz africana. Entre eles, ver Brown (1985) e Birman (1985). A respeito da umbanda no Rio de Janeiro, ver, entre outros, Velho (1975), Brown (1985), Birman (1995) e, mais recentemente, Lucinda (2012). Sobre a umbanda em São Paulo, ver Brumana e Martínez (1991).

${ }^{10}$ Modo de deslocamento característico das entidades espirituais nos terreiros.

${ }^{11}$ Assim como nas irmandades do Itapemirim, a mística do CECP aparece também como influência, singularizando-se aí, em contextos tão diversos quanto o do Santo Daime (Oliveira 2011:173).

${ }^{12}$ Não tenho a intenção de utilizar tais modelos doutrinários para classificar as casas, mas chamar a atenção para a multiplicidade dos agentes que interagem no jogo de reconhecimento e acusação por meio das duas doutrinas. Trabalhando com o batuque em Pelotas (RS), Edgar Barbosa Neto (2012) alerta para a redução com que a postura analítica tem tradicionalmente tratado a multiplicidade das casas. 
13 Os processos de cura umbandista e esotérica diferem-se ritualmente, mas compartilham os movimentos de incorporação dos "males influídos", podendo-se, assim, questionar esta corrente maléfica sobre o motivo do infortúnio. Em seguida, tal corrente é persuadida a deixar o corpo do paciente.

${ }^{14}$ A radiação é o ato de povoar um espaço, uma pessoa ou um coletivo, com fluidos espirituais. $O$ termo é encontrado em outros contextos etnográficos. Ver, por exemplo, Pedreira (2010), para o caso do ritual de lamentação das almas na Chapada Diamantina (BA).

${ }^{15}$ Em função da importância desta etapa do ritual de chegada, quase sempre quem carrega a bandeira do campo de expiação é a diretora ou o diretor - outro título da zeladora ou zelador - da irmandade. No entanto, os postos não são necessariamente fixos.

${ }^{16}$ Segundo alguns jornaleiros, o título "bate-flecha" foi atribuído por um político cachoeirense, provavelmente nos anos 1970, para designar o campo de expiação das jornadas. Seu claro intuito foi afastar os espíritos do ritual e transformá-lo em um grupo folclórico, apto às apresentações públicas junto a outros grupos da região, como as folias de reis e os caxambus - ambos passando pelo mesmo processo de "folclorização". Faço uma discussão deste evento em minha tese (Goltara 2014). Sobre a transformação dos Encontros de Folias em apresentações folclóricas na região, ver Goltara (2010) e Bitter (2010).

${ }^{17}$ O tema da reciprocidade é clássico na antropologia, tendo sido inaugurado por Bronislaw Malinowiski (1978) em sua etnografia sobre o kula nas ilhas Trobriand e teorizado por Marcel Mauss no Ensaio sobre a Dádiva (2003). Desde então, muito se escreveu sobre a dádiva na antropologia em diferentes contextos. Não discutirei aqui as inúmeras convergências teóricas que as jornadas apresentam com o material etnográfico existente sobre o assunto, deixando-o para um próximo momento. Tal discussão é realizada, no entanto, em minha tese de doutorado (Goltara 2014).

${ }^{18}$ Devo esta reflexão a Christine Chaves, em comunicação pessoal, a quem sou muito grato. Nesse sentido, os rituais das jornadas aproximam-se em certos aspectos dos "giros" das folias de Urucuia, no norte mineiro, descritos por Luzimar Pereira. Segundo este autor, certos rituais dos giros, como a "retirada" dos foliões dos pousos, "borram os limites entre o dentro e o fora da residência" tanto quanto entre o "alto" e o "baixo", denotando por tais metáforas os planos espiritual e social respectivamente (Pereira 2011:153-154).

${ }^{19}$ Meu uso do termo "rede" é derivado do uso nativo exposto acima. Sou inspirado também pela actor network theory (ANT) teoria das relações que não define a ação em um sujeito, mas cujo foco está na passagem do fluxo das ações, ou seja, nas mediações - sobre a ANT, ver principalmente Latour (2007).

${ }^{20}$ Entidades particulares que fazem parte da corrente de entidades de um médium ou de sua "coroa". Um médium que tem uma "cabeça firme" cuida da sua missão, realiza suas obrigações rituais dando passagem às suas entidades, alimentando-as e criando condições para que estas possam dar cabo às suas próprias missões.

${ }^{21}$ Das 22 definições da palavra "corrente" no Dicionário Houaiss da Lingua Portuguesa (2001), as duas primeiras aproximam-se do primeiro conjunto de significação, as quatro seguintes do segundo, e as duas seguintes ligam-se a ambos os conjuntos.

22 Discutindo a complexidade teoricamente infinita das redes em paralelo à natureza finita da análise, diz Marilyn Strathern (2014:305): "[e] podem-se sempre descobrir redes dentro de redes; é esta a lógica fractal que faz qualquer comprimento um múltiplo de outros comprimentos ou de um elo numa cadeia uma cadeia de outros elos".

${ }^{23}$ Uma das formas de referência a uma missão é "carregar uma cruz".

${ }^{24}$ Entre a literatura que aborda a força criativa das palavras, ver Austin (1962), Tambiah (1985), Peirano (2002). Sobre a força das palavras em um ritual de lamentação na Chapada Diamantina, ver a dissertação de mestrado de Carolina Pedreira (2010).

${ }^{25}$ Mesa cercada por uma mureta com saída/entrada apenas para o altar e para a porta principal; a função desse cercado é controlar a entrada e a saída das correntes espirituais. Os médiuns sentados ao redor da mesa entram em um estado de "concentração" em que são "radiados" pelas correntes 
espirituais - note-se a semelhança deste trabalho de mesa com um ritual da Barquinha na Amazônia Ocidental que, tal como as irmandades jornaleiras do Vale do Itapemirim e o Santo Daime, foi também influenciada pelo CECP (Araújo 2002). No centro Menino Jesus, as sessões esotéricas e umbandistas são divididas por espaços e momentos: as primeiras ocorrem aos domingos, e as segundas nas quartasfeiras.

${ }^{26}$ Parte essencial da pessoa que nos médiuns é deslocada para dar lugar às entidades. Por vezes, são descritos como "consciência".

${ }^{27}$ Uma passagem de Bruno Latour tem uma interessante proximidade com o conceito esotérico-umbandista de distribuição: "Mas se a ação se desloca, não pertence a qualquer lugar específico; $a$ ação é distribuída, variegada, múltipla, deslocada e continua a ser um enigma tanto para os analistas quanto para os atores" (Latour 2007:60, tradução nossa, grifo nosso).

${ }^{28}$ Como formulado por Ingold (2011:168, tradução nossa, grifo nosso): "Cada lugar, em tal mundo, viria a ser como um desdobramento particular da vida das pessoas, um nexo no fluxo perpétuo de idas e vindas em que consiste suas atividades de vida. E, inversamente, cada pessoa viria a ser um desdobramento da experiência dos lugares que teria habitado e das jornadas entre eles".

${ }^{29}$ Alguns etnógrafos das religiões afro-americanas têm chamado atenção para o tema do movimento nas forças espirituais. Entre outros, ver Banaggia (2015), Holbraad (2006), Ochoa (2010).

Recebido em abril de 2016. Aprovado em maio de 2016.

Diogo Bonadiman Goltara (diogobonadiman@gmail.com) Pós-doutorando no Programa de Pós-Graduação em Ciências Sociais da Universidade Federal do Espírito Santo (PGCS/UFES). Doutor em Antropologia Social pela Universidade de Brasília (UnB). 


\section{Resumo:}

Ligando a corrente: Ensaio sobre a relação entre espiritualidade e socialidade nas irmandades religiosas de matriz africana no Vale do Itapemirim

Partindo de etnografia realizada na região sul do Espírito Santo, este artigo descreve a transversalidade das relações sociais e espirituais entre comunidades remanescentes de quilombos privilegiando o conceito de "corrente espiritual", uma força conjuntiva que atua entre pessoas e entidades invisíveis em várias de suas manifestações. Por meio de coletivos de filhas e filhos de santo que se visitam ritualmente durante todo o ano, conhecidos na região por "bate-flecha", a corrente costura-se entre as comunidades, mantendo um ciclo de obrigações e de poderes que flui entre elas.

Palavras-chave: religiões afro-brasileiras, espiritismo, Espírito Santo, corrente espiritual, esoterismo.

\section{Abstract:}

Linking the chain: Essay about the relation between spirituality and sociality in Afro-Brazilian religious fraternities in the Itapemirim Valley

This paper regards an ethnography realized in the Brazilian southeast state of Espírito Santo and describes the transversality of spiritual and social relations among quilombos remaining communities. It highlights the concept of "spiritual chain", a conjunctive force that acts amid persons and invisible entities. By a ritual calendar that organizes mutual visits and that must be followed by religious fraternities known as "bate-flecha", the spiritual chain sews the communities and reinforces a series of obligations and powers that flows through it.

Keywords: Afro-Brazilians religions, spiritism, Espírito Santo, spiritual chain, esotericism. 